\title{
Incidence and associated factors with traumatic childbirth in postpartum Brazilian woman
}

\author{
Incidencia y factores asociados con el parto traumático en mujer brasileña \\ en el posparto
}

\author{
Carla Fonseca Zambaldi* \\ Amaury Cantilino \\ Federal University of Pernambuco, Brazil \\ Jacqueline Vasconcelos Farias \\ The Professor Fernando Figueira Integral Medicine Institute, Brazil \\ Gustavo Paranhos Moraes \\ Federal University of Pernambuco, Brazil \\ Everton Botelho Sougey \\ Federal University of Pernambuco, Brazil \\ (Rec.: agosto de 2016 - Acept.: diciembre de 2016)
}

\begin{abstract}
Childbirth may be a traumatic experience for some women. This observational study aimed to describe the incidence of traumatic childbirth in two regional maternity services in Brazil. In addition, the study intended to determine characteristics that are associated with traumatic childbirth. A total of 328 women were interviewed, up to 72 hours postpartum, between July and November 2010. Women were screened for Diagnostic and Statistical Manual of Mental Disorders, Fourth Edition (DSMI-IV) criteria for traumatic event using the item A of SCID-I interview for PTSD. Socio-demographic and obstetrical variables, pain score, previous trauma and dissociative experiences in women with and without traumatic childbirth were compared. A total of $53(16.2 \%)$ of the sample fulfilled the criteria for a traumatic event. It observed that some socio-demographic and obstetrical variables may be considered as associated with traumatic childbirth, such as an intermediate level of schooling, high risk pregnancy, obstetrical complications during pregnancy, primiparity, a high pain score, forceps, episiotomy, prematurity, obstetrical complications at birth or with the baby, baby needing hospital care, dissociative experience peripartum, no satisfaction with maternity care, not being well informed of the progress of labor and previous trauma related to urban violence, sexual abuse or domestic violence. Childbirth may be a traumatic event for Brazilian. In this sample traumatic childbirth was associated with pain, previous trauma, dissociative experiences and some socio-demographic and obstetrical variables. Traumatic childbirth constitutes an important mental health problem and need more attention from health.
\end{abstract}

Keywords: post-childbirth-related, post-traumatic stress disorder, educational intervention, specific needs of educational support, educational response, programs of educational reinforcement.

\section{Resumen}

El parto puede ser una experiencia traumática para algunas mujeres. Este estudio observacional tuvo como objetivo describir la incidencia del parto traumático en dos servicios regionales de maternidad en Brasil. Además, el estudio pretendía determinar las características asociadas con el parto traumático. Un total de 328 mujeres fueron entrevistadas, hasta 72 horas después del parto, entre julio y noviembre de 2010. Las mujeres fueron seleccionadas para el Manual Diagnóstico y Estadístico de los Trastornos Mentales, Cuarta Edición (DSMI-IV) para el evento traumático utilizando el ítem A de SCID- entrevisto para estrés postraumático. Se compararon variables sociodemográficas y obstétricas, puntuación de dolor, trauma previo y experiencias disociativas en mujeres con y sin parto traumático. Un total de $53(16,2 \%)$ de la muestra cumplieron los criterios para un evento traumático. Se observó que algunas variables sociodemográficas y obstétricas pueden considerarse asociadas con el parto traumático, como un nivel intermedio de escolaridad, un embarazo de alto riesgo, las complicaciones obstétricas durante el embarazo, la primiparidad, un alto puntaje de dolor, fórceps, episiotomía, prematuridad, obstetricia Lactancia que necesita atención hospitalaria, experiencia disociativa periparto, ausencia de satisfacción con la atención de maternidad, no estar bien informado sobre el progreso del parto y trauma previo relacionado con la violencia urbana, el abuso sexual o la violencia doméstica. El parto puede ser un evento traumático para el brasileño. En esta muestra el parto traumático se asoció con dolor, traumatismo previo, experiencias disociativas y algunas variables sociodemográficas y obstétricas. El parto traumático constituye un importante problema de salud mental y necesita más atención de la salud

Palabras clave: relacionados con el parto, trastorno de estrés post-traumático, intervención educativa, necesidades específicas de apoyo educativo, respuesta educativa, programas de refuerzo educativo.

\footnotetext{
* Correspondencia a: Carla Fonseca Zambaldi, Federal University of Permanbuco, Neuropsychiatry, Professor Moraes Rego, 1235, Cidade Universitária, Recife, 5067091 Brazil. Tel. / Fax: 558134462898. E-mail: carlafza@hotmail.com
} 


\section{Background}

Trauma is an emotional response to a terrible event. Although for many women giving birth is a positive and enjoyable experience, it may be considered an extremely stressful life event and some women may feel traumatized. For some women childbirth is physically and psychologically traumatic and meets Criterion A1 (threat) and A2 (intense emotional response) for Posttraumatic Stress Disorder of the Diagnostic and Statistical Manual of Mental Disorders Fourth Edition (DSM-IV). The Criterion A1 for a traumatic event were the person experienced, witnessed, or was confronted with an event or events that involved actual or threatened death or serious injury, or a threat to the physical integrity of self or others and the Criterion A2 person's response involved intense fear, helplessness, or horror (APA, 1994). Some people are resilient after a trauma, having the ability to maintain an emotional equilibrium. Others have some psychiatric symptoms and then recover. And some, are unable to recover and develop a chronic dysfunction, such those that have Post-Traumatic Stress Disorder (PTSD), characterized by disturbing recurring flashbacks, avoidance or numbing of memories of the event, and hyperarousal (high levels of anxiety).

In 1978, two French obstetricians, Bydlowski and Raoul-Duval, described ten clinical cases of what, in pioneering fashion, they called "la nevrose traumatique post-obstetricale" The clinical cases involved women who had experienced lengthy and difficult childbirth, including the use of forceps and death of the fetus. They noted that these women went on to avoid giving birth again, experienced nightmares and fear of sleeping (Bydlowski \& Raoul-Duval, 1978).

Next, Moleman, van der Hart \& van der Kolk (1992) published reports of three clinical cases in which they describe how "the stress of delivery was sufficient to give rise to post-traumatic symptoms. Moreover, Menage (1993) recruited 500 volunteers in the United Kingdom by newspaper advertisements. These women answered questionnaires on the experience they had had following obstetric and gynecological procedures. One hundred of these women described the procedure as being terrible, very stressful, and out of the ordinary and total of 30 of them were diagnosed as having PTSD. Then, Ballard, Stanley \& Brockington (1995), also in the United Kingdom, published four clinical cases of women who had experienced a difficult childbirth with intense pain, an emergency Caesarian section or death of the fetus and had go on to present with symptoms of PTSD, such as recurrent images of the delivery, nightmares and difficulty relating to the baby.

Currently, traumatic childbirth is reported in about a third of women (Boudou, Séjourné \& Cahmbrol, 2007;
Creedy, Shochet \& Horsfall, 2000; Gamble et al., 2003; Olde et al., 2005; Soet, Brack \& Dilorio, 2003). Dissatisfaction with the care provided by the health team (Creedy et al., 2000; Olde et al., 2005; Soet et al., 2003), lack of support from family or partner (Czarnocka \& Slade, 2000), fear of childbirth (Söderquist, Wijma, Thorbert \& Wijma, 2009), primiparity (Wijma, Söderquist \& Wijma, 1997), a previous history of psychological disorders (Wijma, Söderquist, Wijma, 1997), and peripartum dissociative experiences (Wijma, Söderquist \& Wijma, 1997) are considered risk factors for traumatic childbirth and PTSD. Moreover, obstetric complications such as eclampsia or hemorrhage or obstetric procedures, such as the use of forceps or an emergency Caesarian section (Wijma, Söderquist \& Wijma, 1997), prolonged labor or delivery without adequate analgesia, leading to intense pain (Soet et al., 2003); having had a baby with health problems, that is premature, low-weight or with deformities requiring admission to a neonatal intensive care unit (Holditch-Davis, 2012) are associated factors to the occurrence of traumatic childbirth.

Most studies relating to childbirth trauma and PTSD have been carried out in countries with a different economic and public health situation from that of Brazil. Data about traumatic childbirth in the Brazilian population is still unknown. In Brazil, there are three million births every year, most of them (76\%) in the public health sector. Most of the births occur in hospital and are attended by a gynecologist/obstetrician. Brazil is one of the countries with the highest cesarean section rates, probably because vaginal birth is still treated as though it carried a high risk to women's health and sexual life. Although Brazilian maternal mortality rates have decreased, they are still above the desired levels. At present, Brazil is investing in humanized childbirth care, including the encouragement of non-surgical delivery, breastfeeding, rooming-in, extended family visits, and reduction of excessive technological intervention in the delivery process (Victora et al., 2011).

The aim of this study is thus to assess traumatic childbirth and associated factors in Brazilian women. This was a transversal study using the Structured Clinical Interview for Diagnostic and Statistical Manual of Mental Disorders, Fourth Edition Axis I Disorders (SCID-I) to examine the proportion of women who experienced a traumatic childbirth, and questionnaires to investigate the role of socio-demographic and obstetrical variables, pain, previous trauma and dissociative experience peripartum.

\section{Methods}

The Ethics and Research Committee of the Federal University of Pernambuco's Health Sciences Center approved the study protocol, and a written informed consent was obtained from the participants, once the 
aims and objectives of the study had been explained. It was explained verbally and in writing that participation was voluntary and that refusal to participate would not affect future care.

The sample was contacted in the two regional maternity public hospitals in Recife, Brazil, up to 72 hours postpartum. Data was collected between July and November 2010. The inclusion criteria were women (1) able to speak, read and understand Portuguese; (2) aged over 18 years old; (3) up to 72 hours postpartum; (4) whose baby was alive at the time of the interview. Women were only invited to participate in the study once they met the inclusion criteria. Of the 359 women who were asked to participate, 30 refused and to minimize the confounding factors, we excluded one woman who was currently in treatment for a psychiatric disorder. A total of $328(91.4 \%)$ entered the study.

The women were interviewed by a psychiatrist or a trained nurse and answered questionnaires. The following tools were used:

The women were interviewed about the childbirth using item A for PTSD to assess the criteria for traumatic event. It was used the Structured Clinical Interview for Diagnostic and Statistical Manual of Mental Disorders, Fourth Edition Axis I Disorders (SCID-I). The SCID-I is a semi-structured interview designed to diagnosis of psychiatric disorder (First, Williams, Spitzer \& Gibbon, 2007). The interview was conducted by a psychiatrist or a trained nurse. To asses criterion $A 1$, women were asked if, during labor or childbirth they: had felt their life was threatened or were very worried about the possibility of dying; had felt the baby's life was threatened; had felt that they had suffered psychological damage; had received terrible news, such obstetrical complications, complications with the baby, or that the baby was not healthy. To assess criterion A2 the women were asked if they had felt intense fear, helplessness, or horror during the childbirth. If both Criteria A1 and $\mathrm{A} 2$ were met the diagnosis of traumatic childbirth was done.

A socio-demographic and obstetrical characteristics questionnaire was prepared for this study. The women were interviewed about age, marital status, level of education, professional status, personal psychiatric history, type of birth, time of gestation at birth, parity, previous miscarriage, obstetrical complications, complications with the baby, satisfaction with maternity care, and information about the labor process.

Women were asked to quantify their labor pain level indicanting one number in the Numeric Rating Scale (NRS). The NRS is a $0-10$ pain scale, 0 representing no pain and a score of 10 the worst imaginable pain (Downie et al., 1978).

A dissociative experience refers to phenomena such as depersonalization, derealization, amnesia, out of body experience, altered time perception and body image. It has been found to be a powerful predictor of trauma (Zambaldi et al., 2011). The Peritraumatic Dissociative Experiences Questionnaire self-report version (PDEQ-SRV) consists of 10 items describing dissociative experiences during the occurrence of a traumatic event. Women were asked retrospectively about the occurrence of items during labor or immediately after birth, and asked to rank them on a scale of one to five (1=not at all true, 2=slightly true, 3=somewhat true, $4=$ very true, 5=extremely true), resulting in a score ranging from 10 to 50 . A score above 15 is indicative of significant dissociation (Marmar, Weiss \& Metzer, 1998). The internal consistency of the items was good (alpha=0.79) (Birmes et al, 2005). The PDEQ-10SRV was translated and adapted to Portuguese, and the internal consistency of the Portuguese version was 0.87 (Fiszman et al., 2005).

Prior traumatic event may predispose women to a traumatic birth experience. Thus, The Trauma History Questionnaire (THQ) is applied. It is a series of questions about previous trauma divided into questions covering crime experiences, general disaster and trauma questions, and questions about physical and sexual experiences (Fiszman, Cbizuca, Lanfredi \& Figueira, 2005).

Socio-demographic and obstetrical variables, pain score, previous trauma and dissociative experiences in women with and without traumatic childbirth were compared. Fisher's exact test/chi-square test was used to compare categorical variables, and Mann-Whitney/ Student's t test to compare continuous variables. The comparative analysis of quantitative variables (mean/ median), was employed the Shapiro-Wilk for testing the assumption of normality of the variables involved in the study. Therefore, was employed the Student's t-test, when observed the assumption of normality, so when the assumption was violated was employed the Mann-Whitney test. The comparative analysis between qualitative variables was applied the chi-square test, or the Fisher exact test when the chi-square has been violated. The Odds Ratio and $95 \% \mathrm{Cl}$ were calculated for the variables. All differences were tested with a significance level of 0.05 . Data were analyzed using $R$ v2 version 10.0 .

\section{Results}

\section{Sample characteristics}

The women were aged between 18 and 42 (mean: 25, SD: 5.6). A total of 258 (78.65\%) of the sample were married or cohabiting with a partner, and 142 (43.3\%) were employed. The mean value for years of schooling was 8.8. A total of 133 (40.6\%) had primary schooling or less, 189 (57.6\%) had an intermediate level of school- 
ing, and only six (1.8\%) had completed full university degree. A total of $63(19.2 \%)$ of the women had had a previous miscarriage, $72(22.1 \%)$ had had a high-risk pregnancy, and 169 (51.5\%) had given birth to a previous child (Table 1).

A total of 68 (20.7\%) women were from maternity 1 and 260 (79.3\%) were from maternity 2 . The maternity 1 have more high risk pregnancy $(36.8 \% \times 18.2 \%, p=0.0043)$, more complication during pregnancy $(33.8 \% \times 13.6 \%$, $\mathrm{p}=0.0008)$ and during birth $(13.2 \% \times 5.4 \%=0.0450)$, more prematurity $(27.0 \% \times 10.7 \%, p=0.0194)$, more cesarean section $(73.5 \% \times 31.9 \%, p=0.0000)$, and more traumatic childbirth $(29.4 \% \times 12.7 \%, p=0.0012)$ than the maternity 2

\section{Traumatic childbirth}

The interview about childbirth using SCID-I revealed that a total of 53 women (16.2\%) fulfilled the criteria for having experienced a traumatic event. A total of $18.6 \%$ of the sample had felt their life was threatened or were very worried about the possibility of dying during the childbirth, $34.2 \%$ felt the baby's life threatened, $3.1 \%$ felt they had suffered a psychological injury, 3.7\% received some terrible news, such as obstetrical complications, complications with the baby, or that the baby was not normal. In addition, a total of $16.8 \%$ felt intense fear, $9.8 \%$ helplessness, and $4 \%$ horror.

\section{Variables associated with traumatic childbirth}

The variables associated with the traumatic childbirth occurrence were the following: more years of schooling, high risk pregnancy, obstetrical complication during pregnancy, a high pain score, forceps, episiotomy, prematurity, obstetrical complications at birth or with the baby, baby needing hospital care, peripartum dissociative experience and history of three or more previous traumas (Table 1). Being multiparous, satisfaction with maternity care, being well informed of the progress of labor and considering the medical care to be regular, good or excellent were protective factors for the occurrence of traumatic childbirth (Table 1).

In this sample, a total of $71.1 \%$ of women reported experiencing a previous traumatic event at some time in their lives. The most frequent previous traumas in the sample were related to crimes or urban violence. The previous traumas significantly associated with traumatic childbirth were sexual assault with sexual intercourse [p 0.0012, OR 5.25 (1.88-14.45)]; being in a situation where they feared being killed or seriously injured [p 0.0009, OR 3.02 (1.56-5.74)]; being beaten, "spanked" or pushed by a family member [p 0.0098, OR 2.65 (1.26-6.65)]; seeing dead bodies [p 0.0046, OR 2.36 (1.31-4.32)]; and hearing news of illness or death of a family member or close friend [p 0.0075, OR 2.25 (1.25-4.11)].

\section{Discussion}

A total of $53(16.2 \%)$ of the sample fulfilled the criteria for a traumatic childbirth according to the SCID-I. Previous studies have found a traumatic childbirth rate about 30\%. 6-10 These variations in prevalence appear to be due to the different types of questionnaire measurement used, the time after birth it is measured, and the research sample profile. This study observed a prevalence lower than most of those described elsewhere. One explanation for this difference may be the use of face-to-face interviews based on SCID-I. In a face-to-face interview, it is easier to confirm the accuracy and intensity of the reported symptoms than when using self-report tools. In this study, we only considered the answer as affirmative when the fear of death identified was intense. Another explanation may be the impact of the Brazilian public health policy. As a measure to reduce the maternal mortality rate, Brazil has been investing in humanized childbirth care, enabling more women to have prenatal care, providing doulas during labor and allowing the partner to be present, and providing alternative pain relief methods and taking measures to avoid cesarean section. However, this study observed that it is necessary improve Brazilian staff-patient interactions in order to reduce traumatic childbirth.

In this study, women who were satisfied with intrapartum care and well informed of the progress of labor were significantly less likely to develop traumatic childbirth. Staff-patient interaction is an important aspect of the delivery process, and staff members are responsible for guiding the mother through a physical as well as an emotionally challenging event. It is important to improve good staff-patient interactions during childbirth. It is clear that the aggressive management of childbirth and a failure to understand the emotional process of giving birth can cause real problems. In addition, failing to respect the dignity and privacy of the patient also gives rise to genuine suffering. Previous studies have observed that poor interaction with staff, inadequate intrapartum care and the feeling of be poorly informed were associated with post-childbirth-related PTSD symptoms (Beck, 2004; Creedy et al., 2000; Ford \& Ayers, 2011; van Son et al., 2005). Staff members need to be trained to be aware that the psychological outcome of the birth process is as important as the physical. Ford \& Ayers (2011) observed that support during birth is particularly important for women with history of prior trauma or who have high levels of intervention during birth.

In this sample, a total of $71.1 \%$ of women reported experiencing a previous traumatic event at some time in their lives. Others studies have evidenced that a prior traumatic event may predispose women to a traumatic birth experience (Ford \& Ayers, 2011). However, this is 
Table 1. Socio-demographic and obstetrical variables associated with traumatic childbirth.

\begin{tabular}{|c|c|c|c|c|c|}
\hline Variable & $\begin{array}{l}\text { Traumatic childbirth }^{(\mathrm{a})} \\
(\mathrm{n}=53)\end{array}$ & $\begin{array}{l}\text { No traumatic childbirth } \\
(\mathrm{n}=275)\end{array}$ & P-value ${ }^{(b)}$ & OR & $\mathrm{Cl} 95 \%$ \\
\hline \multicolumn{6}{|l|}{ Sociodemographic variables } \\
\hline Year age (mean) & $24.8(\mathrm{SD}=5.3)$ & $25.1(\mathrm{SD}=5.7)$ & 0.8855 & & \\
\hline Years schooling (mean) & $9.7(\mathrm{SD}=2.0)$ & $8.6(S D=2.7)$ & 0.0064 & & \\
\hline \multicolumn{6}{|l|}{ Years schooling } \\
\hline$<9$ years & $13(24.5 \%)$ & $120(43.6 \%)$ & & & \\
\hline $9-1$ years & $39(73.6 \%)$ & $150(54.6 \%)$ & 0.0107 & 2.4 & $1.26-4.86$ \\
\hline$>11$ years & $1(1.9 \%)$ & $5(1.8 \%)$ & 0.5886 & 1.85 & $0.09-2.68$ \\
\hline \multicolumn{6}{|l|}{ Marital status } \\
\hline Single/divorced/widowed & $14(26.42 \%)$ & $56(20.36 \%)$ & & & \\
\hline Married/cohabiting with a partner & $39(73.58 \%)$ & $219(79.63 \%)$ & 0.3264 & 0.71 & $0.37-1.44$ \\
\hline \multicolumn{6}{|l|}{ Professional status } \\
\hline Unemployed & $33(62.26 \%)$ & $153(55.63 \%)$ & & & \\
\hline Employed & $20(37.73 \%)$ & $122(44.36 \%)$ & 0.3735 & 0.76 & $0.41-1.38$ \\
\hline \multicolumn{6}{|l|}{ Parity } \\
\hline Primiparous & $34(64.15 \%)$ & 135 (49.09\%) & & & \\
\hline Multiparous & $19(35.85 \%)$ & $140(50.90 \%)$ & 0.0467 & 0.54 & $0.29-0.98$ \\
\hline \multicolumn{6}{|l|}{ Trauma previous } \\
\hline \multicolumn{6}{|l|}{ Trauma previous } \\
\hline No & $7(31.21 \%)$ & $88(32.00 \%)$ & & & \\
\hline One & $6(11.32 \%)$ & $44(16.00 \%)$ & 0.35578 & 1.71 & $0.52-5.46$ \\
\hline Two & $5(9.43 \%)$ & $32(11.64 \%)$ & 0.2769 & 1.96 & $0.55-6.60$ \\
\hline Tree or more & $35(66.04 \%)$ & $111(40.36 \%)$ & 0.0017 & 3.96 & $1.77-10.12$ \\
\hline \multicolumn{6}{|l|}{ Obstetric variables } \\
\hline High risk pregnancy & $19(35.85 \%)$ & $53(19.41 \%)$ & 0.0096 & 2.32 & $1.21-4.35$ \\
\hline Pregnancy complication & $17(32.08 \%)$ & $41(15.02 \%)$ & 0.0038 & 2.67 & $1.35-5.15$ \\
\hline $\begin{array}{l}\text { Presence of a companion or } \\
\text { partner during labor }\end{array}$ & $35(67.31 \%)$ & 195 (70.91\%) & 0.6024 & 0.84 & $0.45-1.62$ \\
\hline \multicolumn{6}{|l|}{ Type of birth } \\
\hline Vaginal & $30(56.60 \%)$ & $165(60.00 \%)$ & 0.6449 & 1.15 & $0.63-2.08$ \\
\hline Cesarean section & $23(43.39 \%)$ & $110(40.00 \%)$ & & & \\
\hline Forceps & $6(20.00 \%)$ & $6(3.63 \%)$ & 0.0022 & 6.63 & $1.93-22.85$ \\
\hline Episiotomy & $8(26.66 \%)$ & $86(52.12 \%)$ & 0.0130 & 2.99 & $1.31-7.52$ \\
\hline Obstetrical complication at birth & $16(30.76 \%)$ & $7(2.54 \%)$ & 0.0000 & 17.02 & $6.79-46.94$ \\
\hline Prematurity & $12(22.64 \%)$ & $29(10.55 \%)$ & 0.0174 & 2.48 & $1.14-5.16$ \\
\hline Complication with the baby & $19(36.54 \%)$ & $40(14.54 \%)$ & 0.0003 & 3.38 & $1.74-6.49$ \\
\hline Baby needing hospital care & $21(40.38 \%)$ & $50(18.18 \%)$ & 0.0006 & 3.03 & $1.60-5.70$ \\
\hline \multicolumn{6}{|l|}{ Satisfaction variables } \\
\hline \multicolumn{6}{|l|}{ Satisfaction with maternity care } \\
\hline No & $15(28.31 \%)$ & $22(8.00 \%)$ & & & \\
\hline yes & $38(71.69 \%)$ & $253(92.00 \%)$ & 0.0001 & 0.22 & $0.11-0.47$ \\
\hline
\end{tabular}


Table 1. Socio-demographic and obstetrical variables associated with traumatic childbirth.

\begin{tabular}{|c|c|c|c|c|c|}
\hline \multicolumn{6}{|c|}{$\begin{array}{l}\text { Well informed of the progress of } \\
\text { labor }\end{array}$} \\
\hline No & $21(39.62 \%)$ & 34 (12.36\%) & & & \\
\hline Yes & $32(60.37 \%)$ & $241(87.63 \%)$ & 0.0000 & 0.22 & $0.11-0.42$ \\
\hline \multicolumn{6}{|l|}{ Pain } \\
\hline Score pain (mean) & $8.3(\mathrm{SD}=3.1)$ & $6.7(\mathrm{SD}=3.3)$ & 0.0000 & & \\
\hline \multicolumn{6}{|l|}{ Dissociative experience } \\
\hline $\begin{array}{l}\text { Peritraumatic dissociation } \\
\text { (mean score PDEQ) }\end{array}$ & $15.6(\mathrm{SD}=7.4)$ & $10.7(\mathrm{SD}=1.97)$ & 0.0000 & & \\
\hline
\end{tabular}

the first study that outlines specific types of previous trauma associated with traumatic childbirth. Fearing being killed or seriously injured, seeing dead bodies and hearing news of the injury or death of a loved one were common traumas in this sample and were related to traumatic childbirth. Sexual assault with sexual intercourse and domestic violence were also predictive factors. It is possible that these traumas increase stress during interpersonal interaction and childbirth may bring back memories of a sexual assault, as Ford \& Ayers (2011) conclude.

Childbirth represents a critical event in which there are important factors that may contribute to the women perceiving their experience as traumatic. The obstetrical predictive factors identified were obstetrical complications (such as preeclampsia, failure to progress and a long labor process), high pain, forceps, episiotomy and dissociative experience during labor or immediately after birth. These are situations that increase feelings of fear and insecurity in women and may contribute to trauma. Emergency cesarean section has also been found to be related to traumatic childbirth (Alcorn, O’Donovan, Patrick, Creedy \& Devilly, 2010). On the other hand, in this present study, despite the high rate of cesarean section $(40.6 \%)$, it was not associated with traumatic childbirth. This is probably because, in Brazil, the decision to perform a cesarean section is often strongly influenced by nonmedical factors, and the cesarean culture in Brazil makes women believe that a vaginal birth is a risky and negative experience, whereas cesarean sections represent the best quality care (Nuttall, 2000).

Previous studies have found pain during the initial stages of labor (Soet et al., 2003) or the effective aspect of the pain (Olde et al., 2005) to be predictors of a traumatic birth. Likewise, pain was associated with traumatic childbirth and most of the women in this sample indicated a high level pain on the numeric pain scale $(81.1 \%)$. Peritraumatic dissociation is one of the many defensive processes used by humans in stressful situations. Dissociative symptoms can occur during labor or immediately after birth, and according to some authors, it has been found to be a powerful predictor of traumatic childbirth. The present study also found that a high score on the Peritraumatic Dissociative Experience Questionnaire is related to traumatic childbirth.

Finally, the predictive factors relating to the newborn were prematurity, complications with the baby and the baby needing hospital care. The identification of medical complications in the baby was distressing and contributed to the development of trauma symptoms. Moreover, fear for a child's safety is a hugely powerful emotion and some women are faced with the horrifying possibility of their child's death during the birth process.

Although, the present study provides an important contribution to the national literature on traumatic childbirth, a number of limitations should be pointed out. This was a sample of regional women with a low level of education using the public health service, and these findings are limited to the sample on which they were based. This observational study not investigated causes or consequences of traumatic childbirth. It is important future research in order to investigate PTSD related to childbirth and actions for prevention in the Brazilian context.

\section{Conclusions}

This study had shown that a significant proportion of Brazilian women experience childbirth as a trauma. It observed that some socio-demographic and obstetrical variables may be considered as associated with traumatic childbirth, such as an intermediate level of schooling, high risk pregnancy, obstetrical complications during pregnancy, primiparity, a high pain score, forceps, episiotomy, prematurity, obstetrical complications at birth or with the baby, baby needing hospital care, dissociative experience peripartum, no satisfaction with maternity care, not being well informed of the progress of labor and previous trauma related to urban violence, sexual abuse or domestic violence. 
Traumatic childbirth constitutes an important mental health problem and need more attention from health practitioners in the field of pregnancy, delivery and postpartum care. Effective models for the prediction of Brazilian vulnerable women need to be developed and evaluated. Also, it is necessary to improve interventions aiming the reduction women stress, pain and fear during the labor and delivery. Traumatic childbirth needs to be better understood by health professionals so that it can be preventing, identified early and the women affected can receive support. Women should receive high-quality prenatal care, including emotional support and the provision of information. It is important to identify women who have previously experienced traumas relating to urban violence, sexual abuse, and domestic violence. Furthermore, efforts should also be made to ensure good-quality staff-women relations during childbirth. Women should be listened during labor, and it is important to have doctor and nursing team prepared to discuss her fears and opinions.

\section{References}

Adewuya, A., Ologun, Y. \& Ibigbami, O. (2013). Post-traumatic stress disorder after childbirth in Nigerian women: prevalence and risk factors. BJOG: An International Journal of Obstetrics \& Gynaecology, 113(3), 284-288. doi:10.1111/j.1471-0528.2006.00861.x

Alcorn, K., O'Donovan, A., Patrick, J., Creedy, D. \& Devilly, G. (2010). A prospective longitudinal study of the prevalence of post-traumatic stress disorder resulting from childbirth events. Psychological Medicine, 40(11), 1849-1859. doi:10.1017/S0033291709992224

American Psychiatric Association. (1994). Diagnostic and statistical manual of mental disorders (4th ed.). Washington: Autor.

Ballard, C., Stanley, A. \& Brockington, I. (1995). Posttraumatic stress disorder (PTSD) after childbirth. The British Journal of Psychiatry, 166(4), 525-528. doi:10.1192/ bjp.166.4.525

Beck, C. (2004). Birth trauma: in the eye of the beholder. Nursing Research, 53(1), 28-35. Retrieved from http://journals.Iww.com/nursingresearchonline/Abstract/2004/01000/Birth Trauma In the Eye of the Beholder.5.aspx

Birmes, P., Brunet, A., Benoit, M., Defer, S., Hatton, L., Sztulman, H. \& Schmitt, L. (2005). Validation of the Peritraumatic Dissociative Experience Questionnaire self-report version in two samples of French-speaking individuals expoed to trauma. European Psychiatry, 20(2), 145-151. doi:10.1016/j.eurpsy.2004.06.033

Boudou, M., Séjourné, N. \& Chabrol, H. (2007). Childbirth pain, perinatal dissociation and perinatal distress as predictors of posttraumatic stress symptoms. Gynécologie, obstétrique \& fertilité, 35(11), 1136-1142. doi: 10.1016/j.gyobfe.2007.09.014

Bydlowski, M. \& Raoul-Duval, A. (1978). Un avatar psychique méconnu de la puerperalité: la névrose traumatique post-obstetricale. Perspectives Psychiatriques, 4, 321328.

Creedy, D., Shochet, I. \& Horsfall, J. (2000). Childbirth and the development of acute trauma symptoms: incidence and contributing factors. Birth, 27(2), 104-111. doi:10.1046/j.1523-536x.2000.00104.x

Czarnocka, J. \& Slade, P. (2000). Prevalence and predictors of post-traumatic stress symptoms following childbirth. British Journal of Clinical Psychology, 39(1), 35-51. doi:10.1348/014466500163095

Downie, W., Leatham, P., Rhind, V., Wright, V., Branco, J. \& Anderson, J. (1978). Studies with pain rating scales. Annals of the Rheumatic Diseases, 37(4), 378-381. Retrieved from http://ard.bmj.com/content/37/4/378. long

First, M., Williams, J., Spitzer, R. \& Gibbon, M. (2007). Structure Clinical Interview for DSM-IV-TR Axis I Disorders, Clinical Trials version (SCID TR). New York: Biometrics Research.

Fiszman, A., Cabizuca, M., Lanfredi C. \& Figueira, I. (2005). The cross-cultural adaptation to Portuguese of the Trauma History Questionnaire to identify traumatic experiences. Revista Brasileira de Psiquiatria, 27(1), 63-66. doi:10.1590/S1516-44462005000100014

Fiszman, A., Marques, C., Berger, W., Volchan, E., Oliveira, L., Coutinho, E., ... \& Figueira, I. (2005). Cross-cultural adaptation of the Peritraumatic Dissociative Experiences Questionnaire, Self-Report Version, to Brazilian Portuguese. Revista de Psiquiatria do Rio Grande do Sul, 27(2), 151-158. doi:10.1590/S010181082005000200005

Ford, E. \& Ayers, S. (2011). Support during birth interacts with prior trauma and birth intervention to predict postnatal post-traumatic stress symptoms. Psychology \& Health, 26(12), 1553-1570. doi:10.1080/08870446.2010 .533770

Gamble, J., Creedy, D., Moyle, W., Webster, J., McAllister, M. \& Dickson, P. (2005). Effectiveness of a counseling intervention after traumatic childbirth: a randomized controlled trial. Birth, 32(1), 11-19. doi:10.1111/j.07307659.2005.00340.x

Holditch-Davis, D. (2012). Posttraumatic Stress Symptoms in Mothers of Premature Infants. Journal of Obstetric, Gynecologic, and Neonatal Nursing, 32(2), 161-171. doi:10.1177/0884217503252035

Hosmer, D. \& Lemeshow, S. (2000). Applied logistic regression (2nd ed.). New York: John Wiley \& Sons, Inc.

Marmar, C., Weiss, D. \& Metzler, T. (1998). Peritraumatic dissociative experiences questionnaire. In J. Bremner \& C. Marmar (Ed.), Trauma, memory, and dissociation (pp. 249-252). Washington: American Psychiatric Publishing.

Menage, J. (1993). Post-traumatic stress disorder in women who have undergone obstetric and/or gynaecological procedures: A consecutive series of 30 cases of PTSD. Journal of Reproductive and Infant Psychology, 11(4), 221-228. doi:10.1080/02646839308403222 
Moleman, N., van der Hart, O. \& van der Kolk, B. (1992). The Partus Stress Reaction: A Neglected Etiological Factor in Postpartum Psychiatric Disorders. The Journal of Nervous and Mental Disease, 180(4), 271272. Retrieved from https://www.ncbi,nlm.nih.gov/ pubmed/1556567

Nuttall, C. (2000). Caesarean section controversy. The caesarean culture of Brazil. British Medical Journal, 320, 1072-1074. doi:10.1136/bmj.320.7241.1072/a

Olde, E., van der Hart, O., Kleber, R., van Som, M., Wijnen, H. \& Pop, V. (2005). Peritraumatic dissociation and emotions as predictors of PTSD sympoms following childbirth. Journal of Trauma \& Dissociation, 6(3), 125-142. doi:10.1300/J229v06n03_06

Ryding, E., Wijma B. \& Wijma, K. (1997). Posttraumatic stress reactions after emergency cesarean section. Acta $\mathrm{Ob}$ stetricia et Gynecologica Scandinavica, 76(9), 856-861. doi:10.3109/00016349709024365

Söderquist, J., Wijma, B., Thorbert, G. \& Wijma, K. (2009). Risk factors in pregnancy for post-traumatic stress and depression after childbirth. BJOG: An International Journal of Obstetrics and Gynaecology, 116(5), 672680. doi:10.1111/j.1471-0528.2008.02083.x

Soet, J., Brack, G. \& Dilorio, C. (2003). Prevalence and predictors of women's experience of psychological trauma during childbirth. Birth, 30(9), 36-46. doi:10.3109/00016349709024365 van der Velden, P. \& Wittmann, L. (2008). The independent predictive value of peritraumatic dissociation for PTSD symptomatology after type I trauma: a systematic review of prospective studies. Clinical Psychology Review, 28(6), 1009-1020. doi:10.1016/j.cpr.2008.02.006

van Son, M., Verkerk, G., van der Hart, O., Komproe, I. \& Pop, V. (2005). Prenatal depression, mode of delivery and perinatal dissociation as predictors of postpartum posttraumatic stress: an empirical study. Clinical Psychology \& Psychotherapy, 12(4), 297-312. doi:10.1002/ cpp.446

Victora, C., Aquino E., do Carmo, M., Monteiro, C., Barros, F. \& Szwarcwald, C. (2011). Maternal and child health in Brazil: progress and challenges. The Lancet, 377(9780), 1863-1876. doi:10.1016/S0140-6736(11)60138-4

Wijma, K., Söderquist, J. \& Wijma, B. (1997). Posttraumatic stress disorder after childbirth: a cross sectional study. Journal of anxiety disorders. Journal of anxiety disorders, 11(6), 587-597. doi:10.1016/S08876185(97)00041-8

Zambaldi, C., Cantilino, A., Farias, J., Moraes, G. \& Sougey, E. (2011). Dissociative experience during childbirth. Journal of Psychosomatic Obstetrics \& Gynecology, 32(4), 204-209. doi:10.3109/0167482X.2011.626092 